\title{
Editorial Access and Allocation in Earth System Governance
}

\author{
Joyeeta Gupta ${ }^{1} \cdot$ Louis Lebel $^{2}$
}

Accepted: 12 May 2020 / Published online: 24 May 2020

(c) Springer Nature B.V. 2020

\section{Introduction}

The purpose of this Special Issue on Access and Allocation in Earth System Governance is to undertake a decadal analysis of the literature on the subject since 2008, to harvest lessons learnt, to test some of these ideas and to develop theories on governance. Access refers to "the ability of individuals to secure a basic minimum of resources"; whereas, allocation refers to the distribution of the rest as well as the associated risks and responsibilities (Gupta and Lebel 2010). These ideas are closely related to concepts such as justice, equity, distributive issues and fairness.

Access and Allocation was one of the five analytical themes of the Earth System Governance project during its first decade. The Earth System Governance project was set-up in 2008 under the International Human Dimensions Programme on Global Environmental Change and has close relations with this Programme's follow-up programme-Future Earth. Under its Science Plan (ESG 2009; Biermann et al. 2010), there were five analytical themes including Architecture, Agency, Accountability, Adaptiveness, and Access and Allocation; four cross-cutting issues-namely power, knowledge, norms and scale; and four key thematic areas which include food, water, climate change and the global economic system.

This decadal review assesses the breadth and depth of significant ideas with intellectual merit from different disciplines covering access and allocation written by those in the Earth System Governance family or affiliated with it. Each paper provides an overview of the field and aims to serve as an entry portal to the Earth System Governance literature on access and allocation. Since the terms access and allocation have a range of synonyms in the academic literature - such as human rights, justice, distribution, distributive justice, equity, fairness, etc., and many scholars both within and outside the immediate family of Earth System Governance scholars use these terms instead, the authors were requested to

Joyeeta Gupta

j.gupta@uva.nl

Louis Lebel

llebel@loxinfo.co.th

1 Governance and Inclusive Development Programme, Amsterdam Insitute of Social Science Research, University of Amsterdam, Amsterdam, The Netherlands

2 Unit for Social and Environmental Research, Faculty of Social Sciences, Chiang Mai University, Chiang Mai, Thailand 
also include pertinent lessons learnt from the broader community of scholars working on earth system governance themes.

This Special Issue consists of twelve papers that begin with understanding the epistemological underpinnings of Access and Allocation, and then move on to discuss different systems - the global economic system including reflections on aid, trade and investment, energy and climate, food and water, and biodiversity. Although these papers do not comprehensively cover the different fields, working within their own boundaries, they provide a wealth of information and lessons learnt. This Editorial briefly explains the discussions in the individual papers. The last paper synthesises the lessons learnt from the different papers.

A critical note to be made upfront is that papers have used different approaches to analyse the literature. Some have attempted to cluster the lessons learnt from the literature in terms of access and allocation. Some have operationalized access and allocation and then applied this to a particular problem. And some have interpreted access and allocation in their own way: for example in terms of fair outcomes, effective pathways and redistribution mechanisms (e.g. Scobie, this SI). These three divergent approaches have enhanced the richness of this review. In the final synthesis paper we have tried to draw the common themes and approaches.

\section{Lessons learnt}

Kalfagianni and Meisch examine the epistemological underpinnings of the Access and Allocation framework through the literature on this subject. The authors identified 6o relevant papers for their analysis and argue that assessing what is just or fair in terms of access and allocation depends on subjective views and that many different disciplines can contribute to such an assessment. However, different disciplines may have different logics and it may be difficult to unite these perspectives. Thus, authors may take a conservative versus ideal justice view, a corrective versus distributive justice view, a procedural versus substantive justice view. They argue that the perspective of the author has important implications for how access and allocation have been studied and findings interpreted.

Economic relations, and the treaties and agreements that support such activities, can also affect access and allocation. Defne Gonenc, Dario Piselli, and Yixian Sun argue, based on the papers they have assessed, that trade and investment agreements may both enhance and exacerbate access. The design of tariffs and liberalization processes can reduce access to water and food and can affect farmers and other producers negatively. At the same time, environmental treaties which restrict trade and investment opportunities also have negative impacts on people's access to resources. They also argue that free trade measures can negatively affect the environment and allocation of resources; but show that there is debate between authors regarding the benefits and risks of free trade on allocation.

Michelle Scobie examines trade, investment and aid by reviewing 114 papers focusing on aid. She shows that aid governance architectures take a paternalistic perspective rather than a corrective justice perspective to support developing countries, especially in the case of climate change. Moreover, celebrity aid often masks the systemic drivers of global inequality by focussing on token activities addressing symptoms. Aid instruments also may fail when they search for local solutions for problems which have powerful global drivers. Many papers reviewed question whether aid actually achieves the goals of poverty reduction while addressing environmental challenges. Although the paper takes a different angle 
to assessing trade-Scobie's findings confirm those of the previous paper in terms of how the trade and investment agenda affect access and allocation.

In terms of trade in waste, Benedetta Cotta examines the international waste flows of plastic and electronic waste to argue how rules regarding waste are justified in Western countries and how they negatively affect access and allocation in the developing world. She argues that while some of these waste flows are justified by exporters as they may enhance access to resources in developing countries, in fact they just allocate near endof-life products or difficult to recycle products to the South and shift the risk of dealing with the wastes there. She demonstrates this by analysing discarded electronic and electric equipment (EEE) and plastic waste flows.

Kevin Grecksch and Carola Klöck examine the literature on climate change adaptation to show that access can be used to assess access to basic needs, access to basic rights, and access to decision making; they look at allocation in terms of the allocation of financial resources, the allocation of responsibilities and how adaptation not only minimizes risks but leads to a redistribution of risks through maladaptation but also through ways in which adaptation projects are carried out. They argue that vulnerability is not something innate but is produced by global allocation mechanisms. Although they apply the access and allocation lens to adaptation, they argue that these terms are less intuitive for the adaptation literature and prefer the notion of climate justice.

Antonina Ivanova, Asim Zia, Paiman Ramsan, Mairon Bastos-Lima examine the literature on climate change mitigation to argue that access issues concern the need to address basic needs while reducing greenhouse gas emissions, while allocation is about how climate responsibilities are shared between countries. The paper argues that allocation affects access and that the mechanisms for allocating responsibilities are inadequate for addressing the climate problem; and that the scenarios of greenhouse gas emissions into the future that have been developed often inadequately represent the challenges faced by developing countries and therefore may lead to inappropriate decisions.

In terms of energy and climate mitigation, Joyeeta Gupta, Arthur Rempel and Hebe Verrest zero in on how investors and shareholders in the fossil fuel industry behave and how this affects access and allocation. The authors look at the specific role of Pension Funds and Export Credits to argue that there are five choices available to these investors/shareholders with differing impacts on access and allocation-but that only the option of writing off investments in fossil fuel is responsible. The other options are either ignoring the impacts of investing in fossil fuel; selling shares in fossil fuels to others including developing country actors; and supporting investments in fossil fuels in the developing world through trade, aid and investment. These options create long-term financial and infrastructural lock-in or transfer the risk of stranded assets to the South along with the growing risk of the impacts of climate change.

Dona Azizi who looks at scholarship on food sees access in terms of food security and allocation in terms of food systems. She argues that food security, food systems and food sustainability are closely related, but that their governance systems are fragmented. Such fragmentation in norms and institutions is influenced by power and affects access to and allocation of resources.

In terms of water, Margot Hurlbert focuses on the issue of water for drinking and sanitation. She concludes that although there is considerable literature on access to drinking water and sanitation and to related procedures, this literature does not adequately address the issues of sanitation or the relationships with other water related issues or other rights. The allocation of resources and related procedures for water and sanitation services is developing but Hurlbert argues that the literature has so far not been able to suggest 
possible solutions for how the access and allocation issues with respect to drinking water and sanitation can be addressed.

On biodiversity, Brendan Coolsaet, Neil Dawson, Florian Rabitz and Simone Lovera, show that although applying access and allocation to this field is challenging as the terminology is different, it is possible. They discuss issues of access to resources and access and benefit sharing mechanisms and other mechanisms such as integrated conservation and development projects, and payments for ecosystem services to argue that these mechanisms try to address equity issues but are often unsuccessful. They also see the close relationship between access and allocation and find separating these problematic.

Pritee Sharma and Salla Nithyanath Kumar discuss allocation and access issues in relation to the nexus between water, energy and food. They argue, based on their review of the literature, that policy coordination and effective stakeholder participation between the different fields is vital to addressing the problems of inequitable access and allocation. They recommend for instance that the rights to water, food and energy should be seen as a composite right.

The final synthesis paper by Gupta and Lebel argues that although in some fields access and allocation may appear to be unintuitive terms, this paired framework enables unpacking socio-ecological justice issues. It helps also to expose the fact that while the Sustainable Development Goals prioritize access issues, they do not address the redistribution challenges that allocation brings up. This is paternalistic and does not address the point that many authors have raised in this Special Issue-which is that current mechanisms of allocation through markets, trade, investment, aid, and international treaties-may themselves be responsible for exacerbating the challenges of access. Furthermore, sectoral and incremental governance is unable to address the systemic nature of socio-ecological challenges.

\section{Conclusions}

The papers have taken distinct approaches that either assess the literature on a specific topic using the access and allocation approach, or they apply the access and allocation lens to assessing specific topics or they engage with a hybrid approach. The reasons for doing so is that authors have often used distinct terminology to address access and allocation issues-some focusing on access and others on allocation, and yet others using the language of social and environmental justice, equity and/or ethics.

Nevertheless we draw two conclusions: First, in the presence of a wide variation in epistemologies, vocabularies and approaches, this set of papers shows that despite good intentions (e.g. trade aims at reducing the costs of goods making them affordable for all; aid aims at allocating resources to the poor and/or the Global South with the intention of addressing social and ecological challenges; environmental treaties ostensibly address environmental issues in a fair manner), socio-ecological inequalities are being sharpened. This may be because of the disparities in the underlying themes-some see justice as corrective and others as distributive or because an emphasis on fair procedures may not automatically lead to fair outcomes. It may also be because trade, investment, aid and treaty negotiation processes are very entrenched within a neo-liberal capitalist narrative.

Second, the question is whether the 'access and allocation' conceptualization adds value to the analysis of social and environmental justice issues. Clearly it still has limited popularity as many authors prefer to use their own disciplinary vocabulary. However, there is clearly a need to develop a common overarching framework that can help more 
systemic and comparative analysis of issues across fields, especially as the scholarship and the SDGs talk of the systemic nature of current global social, economic and ecological challenges. We could argue thus that the access and allocation framework can potentially enable greater operationalization of socio-ecological justice issues that is more relevant for comparative analysis of different fields, that exposes the narrow focus on access at the cost of allocation issues across different fields, and that can be used for a more systemic analysis.

\section{Reference}

Biermann, F., Betsill, M. M., Gupta, J., Kanie, N., Lebel, L., Liverman, D., Schroeder, H., Siebenhüner, B., \& Zondervan, R. (2010). Earth system governance: A research framework. INEA, 10(4), 277-298.

ESG. (2009). Earth system governance: People, places, and the planet. Science and implementation plan of the Earth System Governance Project. Earth System Governance Project Report 1. IHDP Report 20, Bon.

Gupta, J., \& Lebel, L. (2010). Access and allocation in earth system governance: Water and climate change compared. International Environmental Agreements, 10, 377-395.

Publisher's Note Springer Nature remains neutral with regard to jurisdictional claims in published maps and institutional affiliations. 